\title{
Endocranial Suppurations of Sinus Origin: Ratio of 3 Cases in Children at the Hospital in Mali
}

\author{
Bourama Kané ${ }^{*}$, Korotoumou Wélé Diallo1, Mohamed Maba Traoré2, Boubacar Mami Touré2, \\ Mahamadou Dama3, Mody Abdoulaye Camara², Guédiouma Dembélé1, Daouda Sissoko33, \\ Oumar Coulibaly ${ }^{3}$, Mamadou Traoré 4
}

${ }^{1}$ Pediatrics Department of Mali Hospital, Bamako, Mali

${ }^{2}$ Medical Imaging Service, Bamako, Mali

${ }^{3}$ Neurosurgery Department of the Mali Hospital, Bamako, Mali

${ }^{4}$ Pediatric Service of the Commune Reference Health Center V, Bamako, Mali

Email: ^bkanebassidiki.bk@gmail.com

How to cite this paper: Kané, B., Diallo, K.W., Traoré, M.M., Touré, B.M., Dama, M., Camara, M.A., Dembélé, G., Sissoko, D., Coulibaly, O. and Traoré, M. (2021) Endocranial Suppurations of Sinus Origin: Ratio of 3 Cases in Children at the Hospital in Mali. Open Journal of Pediatrics, 11, 517-531.

https://doi.org/10.4236/ojped.2021.113048

Received: August 10, 2021

Accepted: September 25, 2021

Published: September 28, 2021

Copyright $\odot 2021$ by author(s) and Scientific Research Publishing Inc. This work is licensed under the Creative Commons Attribution International License (CC BY 4.0).

http://creativecommons.org/licenses/by/4.0/

\begin{abstract}
Introduction: Intracranial suppurations are neoformed purulent collections including, in decreasing order, cerebral abscesses, subdural empyemas and extradural empyemas. Otorhinolaryngologic infections are one of the main causes, especially in older children and adolescents. We report 3 clinical cases of endocranial suppurations treated at the Mali Hospital. Clinical Cases: 1) Observation 1. IK was a 14-year-old boy, who was hospitalized in our department for fever, headache and left hemiplegia. The emergency brain scan showed a right frontal and interhemispheric subdural empyema associated with multifocal sinusitis. Surgical drainage associated with ceftriaxone: 100 $\mathrm{mg} / \mathrm{Kg} / \mathrm{d}$ in direct intravenous (DI), metronidazole: $10 \mathrm{mg} / \mathrm{Kgs} / 12 \mathrm{hours}$ in slow intravenous (SI) for 15 days, gentamycin: $3 \mathrm{mg} / \mathrm{Kgs} / \mathrm{d}$ in SI for 3 days, paracetamol $15 \mathrm{mg} / \mathrm{Kgs} / 6$ hours in SI, $10 \%$ glucose serum: $100 \mathrm{ml} / \mathrm{Kg} / \mathrm{d}$ were given. The bacteriological analysis of the pus came back sterile. The postoperative period was calm. 2) Observation 2. This was a 14-year-old boy with a history of headaches who was admitted to our department for left hemiplegia. An emergency brain scan showed a right pre-suppurative encephalitis associated with a right fronto-ethmoidal and maxillary sinusitis. He was put on ceftriaxone $100 \mathrm{mg} / \mathrm{kg} / \mathrm{d}$ in DI for 21 days, gentamycin: $3 \mathrm{mg} / \mathrm{Kg} / \mathrm{d}$ in SI for 3 days; metronidazole: $10 \mathrm{mg} / \mathrm{kg} / 12$ hours in SI for 21 days, paracetamol: $15 \mathrm{mg} / \mathrm{kg} / 6$ hours in SI. After 3 weeks of medical treatment, a follow-up brain scan revealed an interhemispheric and right subdural empyema. Surgical drainage was associated with the triple antibiotic therapy initially instituted. The bacteriological analysis of the pus was sterile. The postoperative course was calm. 3) Observation 3. N.M was an 11-year-old boy, who was admitted
\end{abstract}


with fever and left hemiplegia. An emergency brain scan revealed a right hemispheric subdural empyema associated with an intracerebral abscess and pansinusitis. Surgical drainage associated with ceftriaxone $100 \mathrm{mg} / \mathrm{kg} / \mathrm{d}$ in DI for 15 days, gentamycin; $3 \mathrm{mg} / \mathrm{kg} / \mathrm{d}$ in SI for 3 days, metronidazole: 10 $\mathrm{mg} / \mathrm{kg} / 12 \mathrm{hours}$ in SI for 15 days and paracetamol: $15 \mathrm{mg} / \mathrm{kg} / 6 \mathrm{hours}$ in SI were instituted. Staphylococcus aureus was isolated in the pus of the abscess. The postoperative course was calm. Conclusion: Endocranial suppurations of sinus origin are serious and frequent infections in children in developing countries. Its diagnosis must be evoked in front of any hemiplegia associated with a fever or headache and confirmed by a cerebral scanner.

\section{Keywords}

Sinusitis, Endocranial Suppurations, Mali Hospital

\section{Introduction}

Intracranial suppurations are neoformed purulent collections including, in decreasing order, cerebral abscesses, subdural empyemas and extradural empyemas [1]. Cerebral abscesses are focal suppurations due to a bacterial infection and developed within the parenchyma. Empyemas are suppurated, extracerebral septate collections (extra and subdural) [2] [3].

The advent of new imaging techniques (scanner, magnetic resonance imaging) allowing early diagnosis with topographic precision of lesions, better knowledge of the bacteria responsible, and the discovery of new antibiotics with good diffusion in the cerebral parenchyma have improved the prognosis of these intracranial suppurations [4] [5].

Otorhinolaryngologic infections are one of the main causes, particularly in older children and adolescents. This gateway has become rare in Western countries. In these countries the epidemiological and clinical characteristics of intracranial suppurations are well established and their prognosis has been greatly improved thanks to progress in their management [1].

Intracranial suppuration is predominant in children in developing countries. This predominance is related to the unfavorable socio-economic conditions in these countries where rapid access to specialized care is not the most common [6] [7].

We report 3 clinical cases of endocranial suppurations treated in the neurosurgery and pediatrics departments of the Hospital of Mali.

\section{Clinical Cases}

\subsection{Observation 1}

IK was a 14-year-old male child who was hospitalized with left hemiplegia. $\mathrm{He}$ lived in a low-income family because his father was a street vendor and his mother was a housewife. His parents had no known medical or surgical history. 
IK was the fifth child of nine siblings. His siblings were doing well. He had no significant personal history. The onset of illness was about two weeks ago, marked by an unquantified fever, episodes of early postprandial vomiting, and intense diffuse headache, prompting a visit to a doctor's office where he was treated for suspected malaria. He was put on quinine salts 0.40 in $400 \mathrm{ml}$ of $10 \%$ glucose serum infused over 2 hours for 3 days. When the signs persisted, he was referred to us for treatment. At the entrance, he weighed $35.5 \mathrm{~kg}$. He had hyperthermia at $38.6^{\circ} \mathrm{C}$. His thorax was symmetrical without any sign of respiratory struggle. His respiratory frequency was $23 \mathrm{cycles} / \mathrm{min}$, oxygen saturation was 95\% under air. Heart sounds were well perceived with regular tachycardia at 110 beats/min. His blood pressure was 100/70 mm Hg. His consciousness was altered with a Glasgow score of 11/15 with left mydriasis. He had a motor deficit of the left hemicorps with conservation of sensitivity. The rest of the clinical examination was without great particularity.

In summary, it was a 14-year-old adolescent with no known medical-surgical history, admitted with fever, headache, vomiting, in whom the clinical examination found a left hemiplegia. Three diagnostic hypotheses were discussed, namely cerebral abscess, bacterial meningitis, and severe neurological malaria. An emergency brain scan showed right frontal and inter-hemispheric subdural empyema associated with multifocal sinusitis (Figures 1(a)-(c)) and (Figures 2(a)-(c)).

- Right intra-orbital fluid collection measuring $27 \times 16 \mathrm{~mm}$ with a regular wall and strongly enhanced by the contrast agent responsible for a mass effect on the eyeball and the right oculomotor muscle.

The complementary exams carried out on admission were:

- The blood count showed a hyperleukocytosis at $25,000 / \mathrm{mm}^{3}$ with predominantly neutrophilic with a hemoglobin level of $14.4 \mathrm{~g} / \mathrm{dl}$, normal platelets. The C-reactive protein was positive at $12 \mathrm{mg} / \mathrm{l}$;

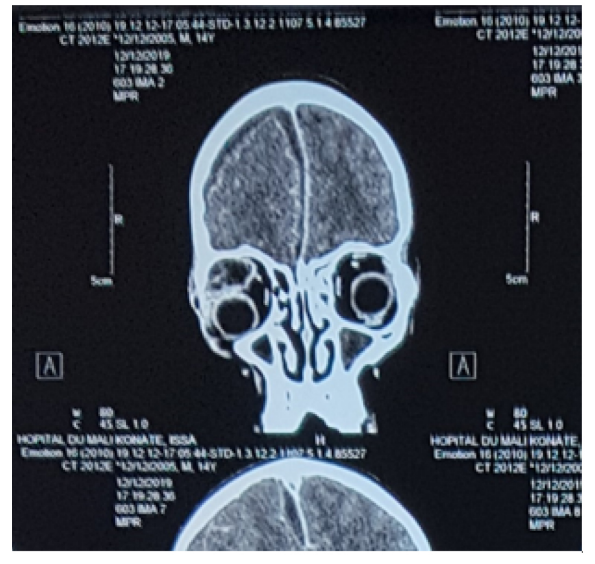

(a)

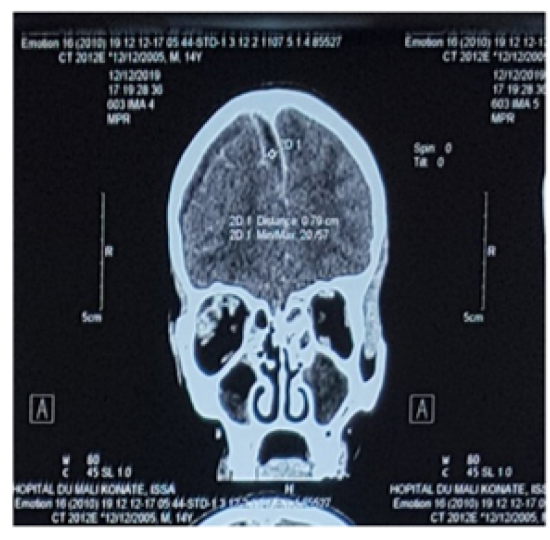

(b)

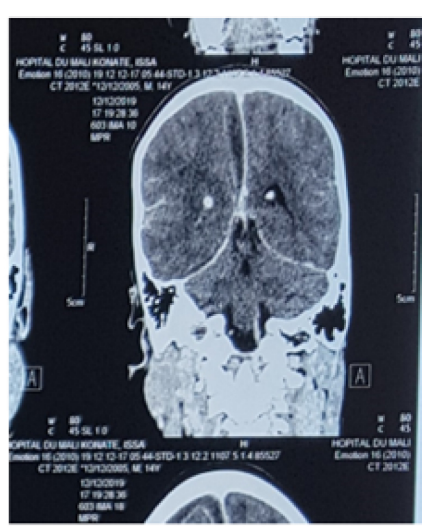

(c)

Figure 1. Brain scan: coronal section after contrast injection: peri-cerebral fluid hypodense collection crescent in the interhemispheric space, right frontal seat diffusing in the interhemispheric space along the scythe of the brain measuring $7 \mathrm{~mm}$ in diameter with peripheral contrast and mass effect on the adjacent parenchyma. 


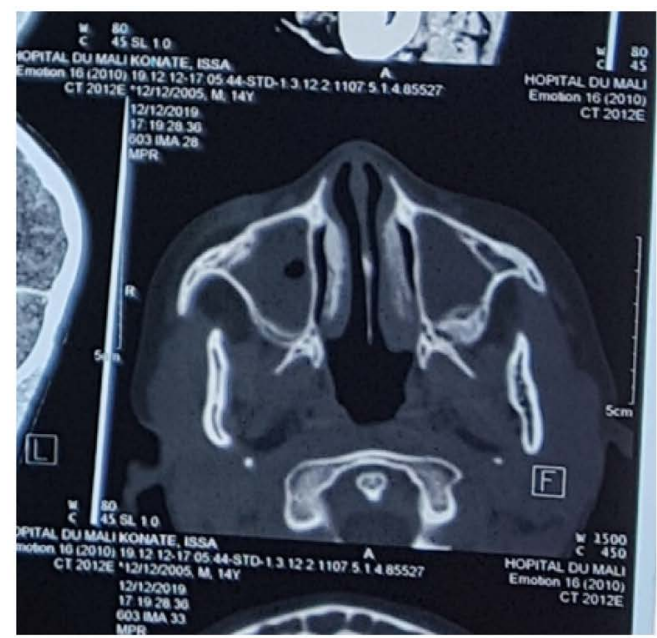

(a)

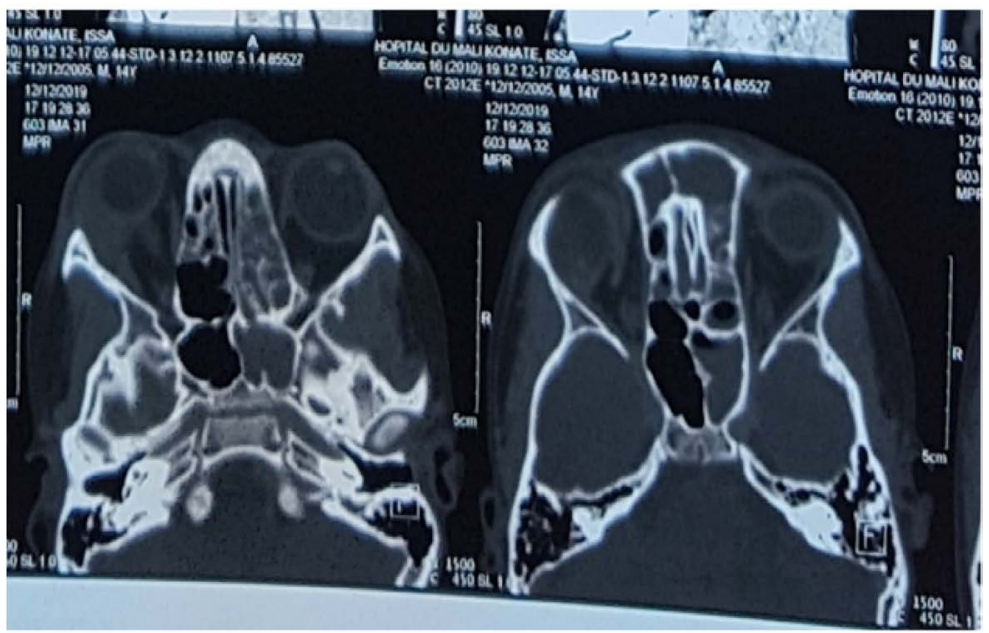

(b)

(c)

Figure 2. Brain scan: axial section in bone window: filling of all the sinuses of the face and the base of the skull except the right sphenoidal sinus.

- Thick drop for plasmodium was negative.

The diagnosis retained was a right frontal and inter-hemispheric subdural empyema with a sinus portal. He was operated in emergency. The surgical technique was as follows:

- right parietal temporo-fronto-parietal incision, skin flap;

- realization of two drill holes, followed by the temporo-fronto-parietal craniotomy;

- opening of the dura mater and from abundant frank pus, evacuation of the pus;

- exploration of the right hemispherical space which contained pus that is sucked out;

- rinsing with saline $0.9 \%$;

- closure of the dura mater by doing an enlargement Duroplasty with the galea;

- repositioning of the flap which remained floating because of the edema;

- and finally, closure of the skin in two planes on a subcutaneous drain with semi-suction and dressing.

The cytobacteriological examination of the pus had returned sterile. After the intervention it was transferred to intensive care where a medical treatment associating ceftriaxone: $100 \mathrm{mg} / \mathrm{Kg} /$ day once in direct intravenous, metronidazole injection: $10 \mathrm{mg} / \mathrm{Kgs} / 12$ hours in slow intravenous for 15 days, gentamycin: $3 \mathrm{mg} / \mathrm{Kgs} / \mathrm{d}$ in slow intravenous once for 3 days, paracetamol injection $15 \mathrm{mg} / \mathrm{Kgs} / 6$ hours in slow intravenous, glucose serum 10\%: $100 \mathrm{ml} / \mathrm{Kg} / \mathrm{day}$ was instituted.

During his stay in intensive care the evolution was marked by the persistence of a vigilance disorder, associated with convulsive crises. He was put on sodium valproate: $1 \mathrm{mg} / \mathrm{Kg} / 12$ hours by slow intravenous administration and gabapentin $100 \mathrm{mg} / \mathrm{Kg} / 8$ hours by direct gastric gavage resulting in an improvement in vi- 
gilance and convulsions. After 15 days of intensive care treatment, he was transferred to the neurosurgery department for further treatment, including antibiotic therapy and motor physiotherapy. The cerebral control CT scan was performed 30 days after the operation. It showed an increase in the volume of the empyema (Figure 3).

A 2nd surgery was performed. It was performed under general anesthesia with the head on the left side. A right posterior para-sagittal skin incision was made, followed by trepanation, opening of the dura mater and introduction of a cushing trocar into the suppurated cavity. Approximately 30 milliliters of frank pus were removed. We finally proceeded to close the empyema in one plane after washing with $0.9 \%$ saline. The evolution was marked by apyrexia, improvement of the motor deficit and headache. The control brain scan showed a total resorption of the empyema (Figure 4). The patient was discharged after 37 days of hospitalization on ciprofloxacin $20 \mathrm{mg} / \mathrm{Kg} / \mathrm{d}$ po for 4 weeks and metronidazole $20 \mathrm{mg} / \mathrm{Kg} / \mathrm{d}$ po for 4 weeks.

Fifteen days after his discharge, he came for consultation with apyretic convulsion and difficulties in concentration in class. The clinical examination was normal except for a slight left motor deficit. He was put on sodium valproate 10 $\mathrm{mg} / \mathrm{Kg} / 12$ hours orally for 24 months and reinforcement of motor physiotherapy.

Twenty months after surgery, he came for follow-up. There were no major complaints to date other than school dropout. On clinical examination, he was in good general condition. The scar from the surgical wound was clearly visible with a depression of the right temporal bone. He was conscious, coherent and well oriented. There was no hemiplegia. Motor skills and sensitivity of the left hemisphere were well preserved. Reflexes were normal.

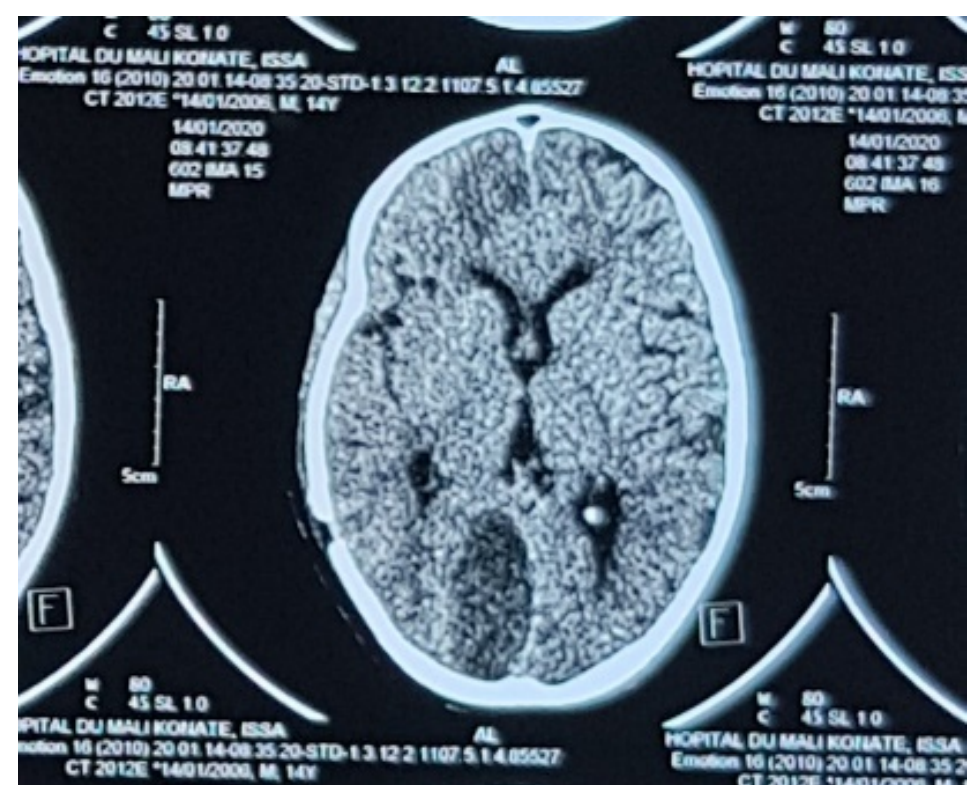

Figure 3. Cerebral scan, axial section after injection of contrast medium: total resorption of right frontal subdural empyema but slight increase in falcorial empyema. 


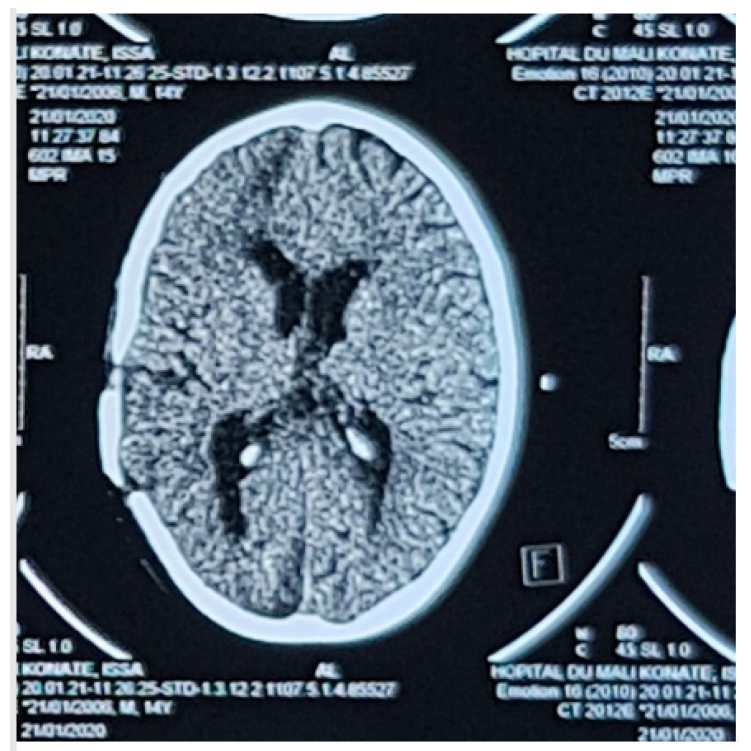

(a)

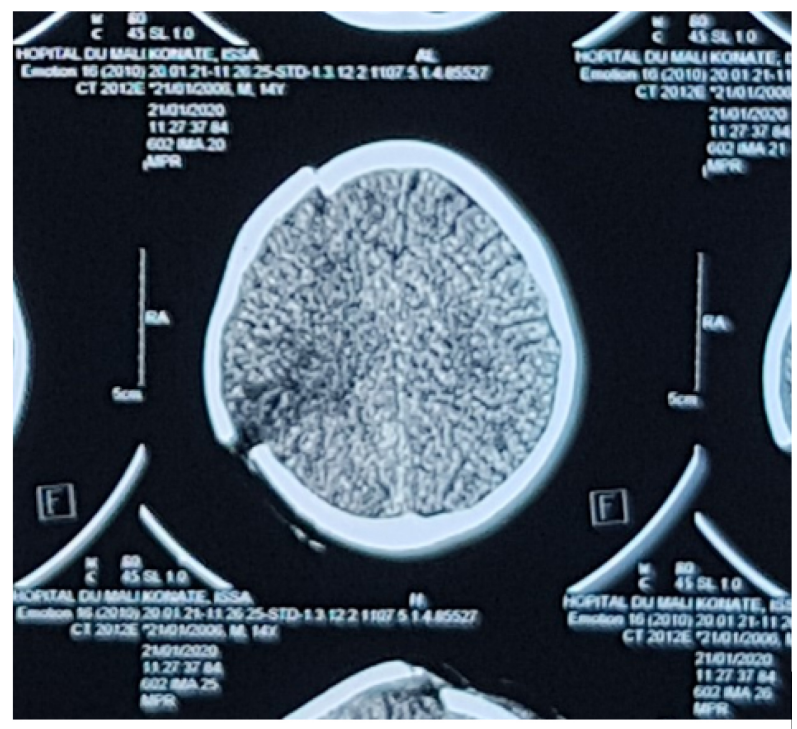

(b)

Figure 4. Cerebral CT scan, axial section without injection of contrast material passing through the lateral ventricles and parietal lobes: total resorption of empyema associated with hypodense cortical, frontal, parietal and right occipital areas related to old areas of ischemia and/or contusion.

\subsection{Observation 2}

HD was a 14-year-old male child who was hospitalized with left hemiplegia. He lived in a low-income family because his father was a rancher and his mother was a housewife. His parents had no known medical or surgical history. HD was the sixth child in a sibling group of five. His siblings were doing well. In his personal history we noted chronic rhinorrhea. The onset of the disease was about a week ago, marked by intense right periorbital irradiation headache treated with herbal decoctions without success. Faced with a febrile convulsion his family brought him to the regional hospital of Segou where he was put on ceftriaxone: 1 $\mathrm{g}$ /day direct intravenous, artesunate $2.4 \mathrm{mg} / \mathrm{Kg} / 12$ hours on the 1 st day then 2.4 $\mathrm{mg} / \mathrm{Kg} /$ day direct intravenous and dexamethasone $0.3 \mathrm{mg} / \mathrm{Kg} /$ day direct intravenous. On the second day of this treatment a left motor deficit was noted by his parents, which motivated his referral to our department. At the entrance, he weighed $42 \mathrm{Kg}$ for a height of $160 \mathrm{~cm}$. His body mass index was 16 normal for his age. He had hyperthermia at $39^{\circ} \mathrm{C}$. His thorax was symmetrical. He had a polypnea at 35 cycles/mn. Oxygen saturation was $95 \%$ under air. Vesicular murmur and well-perceived heart sounds with regular tachycardia at 105 beats/mn. He was conscious, coherent and well oriented. He had left hemiplegia with retained peripheral tenderness. He had left axial exophthalmos. Pupils were normal. The rest of the clinical examination was unremarkable.

In summary, this was a 14 year old adolescent with a history of rhinorrhea who was admitted for headache, convulsion and fever at $39^{\circ} \mathrm{C}$ in whom the clinical examination revealed left hemiplegia. We mentioned three diagnostic hypotheses, namely a severe neurological form of malaria, bacterial meningitis and a 
cerebral abscess. An emergency brain scan showed right pre-suppurative encephalitis associated with a bi fronto-ethmoidal sinusitis and right maxillary sinusitis (Figures 5(a)-(d)).

The complementary exams carried out on admission were:

- Blood count which showed a hyperleukocytosis at $18,000 / \mathrm{mm}^{3}$ with predominantly neutrophilic with moderate anemia at $11.9 \mathrm{~g} / \mathrm{dl}$ normocyte and normochrome. Normal platelets $414,000 / \mathrm{mm}^{3}$. C-reactive protein was elevated $200.6 \mathrm{mg} / \mathrm{l}$;

- Thick drop for plasmodium was negative;

- The blood ionogram showed hyponatremia at $129 \mathrm{mmol} / \mathrm{l}$ with normal kale$\mathrm{mia}$ at $3.75 \mathrm{mmol} / \mathrm{l}$. The creatinemia was $60 \mu \mathrm{mol} / \mathrm{l}$.

Prothrombin level was 50\% and activated partial thromboplastin time was 28.8 seconds.

The diagnosis was pre-suppurative encephalitis. Medical treatment consisted of ceftriaxone $100 \mathrm{mg} / \mathrm{kg} /$ day direct intravenous for 21 days; gentamycin: 3 $\mathrm{mg} / \mathrm{kg} /$ day diluted in $8 \mathrm{ml}$ of saline $0.9 \%$ slow intravenous in a single injection for 3 days; metronidazole: $10 \mathrm{mg} / \mathrm{kg} / 12$ hours slowly intravenous for 21 days, paracetamol: $15 \mathrm{mg} / \mathrm{kg} / 6$ hours if fever and/or headache, glucosated serum $10 \%$ : $100 \mathrm{ml} / \mathrm{kg}$ /day slowly intravenous was instituted.

After 3 weeks of treatment we observed apyrexia, persistence of headache, hemiplegia and left exophthalmos. The control brain scan revealed an interhemispheric and subdural right empyema (Figures 6(a)-(d)).

Surgical treatment combined with medical treatment comprising ceftriaxone $100 \mathrm{mg} / \mathrm{kg} /$ day direct intravenous for 15 days; gentamycin: $3 \mathrm{mg} / \mathrm{Kg} / \mathrm{day}$ slow intravenous diluted in $8 \mathrm{ml}$ saline $0.9 \%$, in a single injection for 3 days; metronidazole: $10 \mathrm{mg} / \mathrm{kg} / 12$ hours slowly intravenous for 15 days, paracetamol: 15 $\mathrm{mg} / \mathrm{kg} /$ hhours slowly intravenous if fever and/or headache, serum glucose $10 \%$ : $100 \mathrm{ml} / \mathrm{kg} /$ day slowly intravenous were instituted.

The surgical treatment under general anaesthesia consisted in placing the patient in supine position with the head turned to the left and fixed on a horseshoe headrest. A right parietal fronto arciform incision and a right frontal craniotomy were performed. The opening of the dura mater was allowed to come from pus

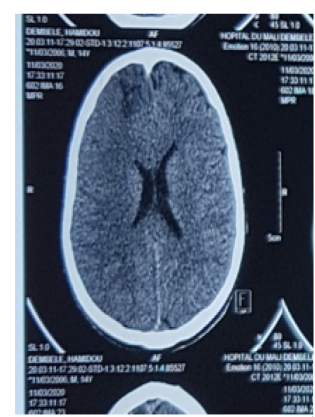

(a)

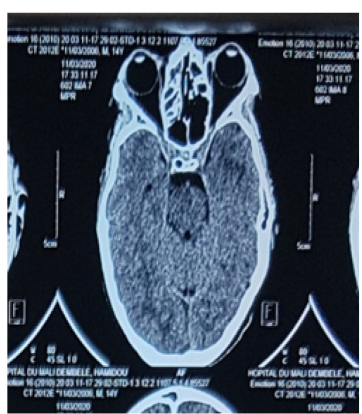

(b)

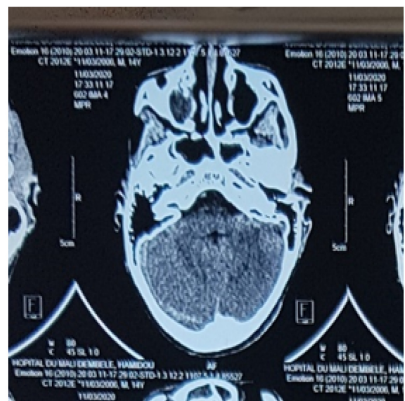

(c)

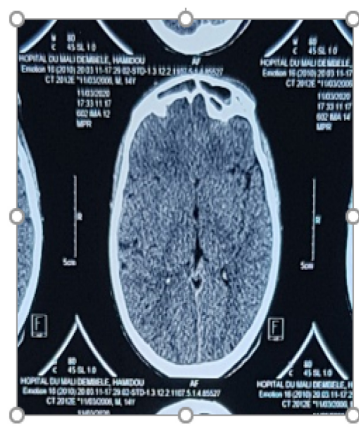

(d)

Figure 5. Cerebral CT scan axial section showing a poorly limited cortico-subcortical right subcortical hypodense range suggestive of presuppurative encephalitis associated with bi fronto-ethmoidal sinusitis and right maxillary sinusitis. 


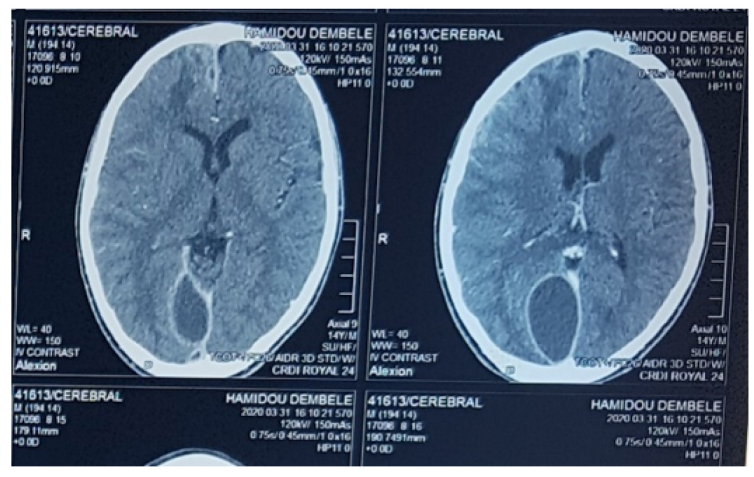

(a)

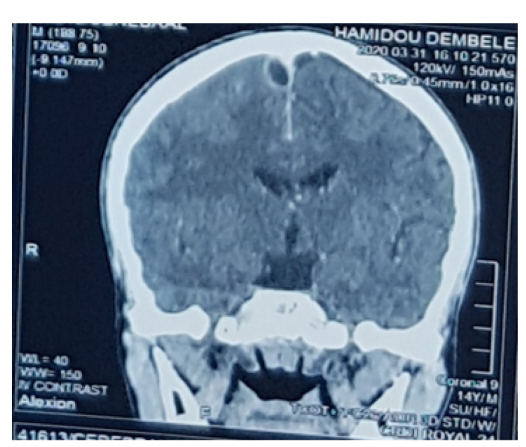

(c)

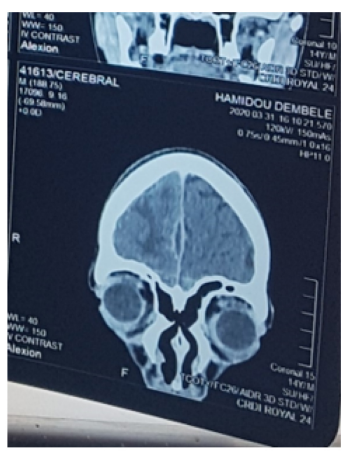

(d)

Figure 6. Cerebral CT scan axial and coronal sections after contrast injection showing a posterior falcarial oval collection with intense annular contrast and slight mass effect on the right occipital lobe associated with 2 small anterior falcarial anterior and right frontal extra dural abscessed collections.

that was aspirated. The cytobacteriological examination of the pus had returned sterile. After the operation it was transferred to the intensive care unit. After 2 days of intensive care treatment, the evolution was marked by the emergence of consciousness, apyrexia, improvement of headache and exophthalmos. He was transferred to the department to begin motor physiotherapy and continue antibiotic therapy: ciprofloxacin $10 \mathrm{mg} / \mathrm{Kg} / 12$ hours for 6 weeks by oral route. The brain scan performed one week after the operation showed a range of subacute right upper parietal cortical hypodense with slight cortical atrophy and small cerebral hernia through the craniotomy slit (Figure 7(a) and Figure 7(b)).

One month after discharge, he was seen in consultation for soft frontoparietal swelling. On clinical examination, he was in good general condition. We noted a post-surgical right frontoparietal flap, mild amyotrophy and decreased motor strength of the left upper extremity with hooked fingers. Sensitivity was preserved.

Seventeen months after discharge he was operated on for frontoparietal flap. The operation consisted of making a horseshoe-shaped incision around the right frontal flap under general anesthesia, lifting the skin flap and the flap. Then 3 holes were made on the flap and on the skull by trans-bone thread. Finally, the skin was closed in 3 planes and a dressing was applied. The postoperative period was calm. The follow-up brain scan performed 15 days after surgery showed a left parietal sequelae hypodense image opposite the cranial flap (Figures 8(a)-(c)).

\subsection{Observation 3}

N.M. was an 11-year-old male child admitted with fever and left hemiplegia. His parents worked in the informal sector. They had no known medical or surgical history. NM was the first child of a sibling group of 6 , and his siblings were well. He came from a low-income family. He was dropped out of school by his parents. In his history we noted chronic headaches. The onset of the illness was about 15 days ago marked by an unquantified fever, intense diffuse headache 


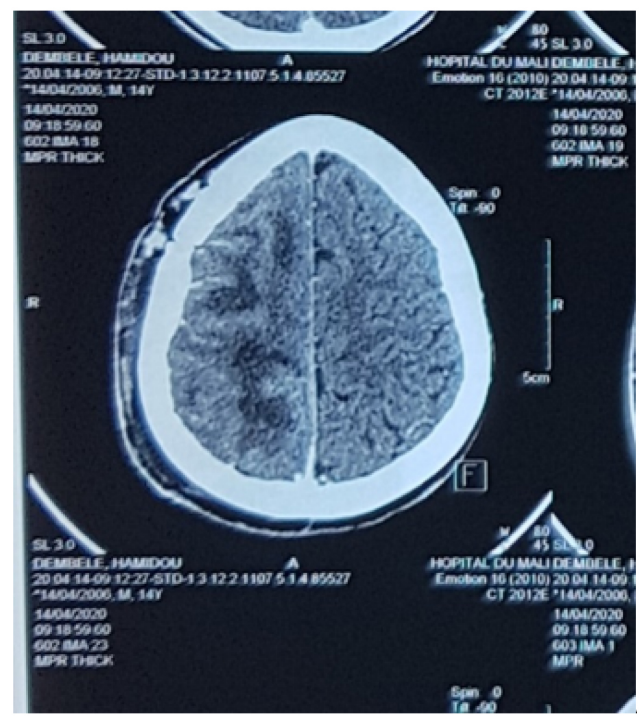

(a)

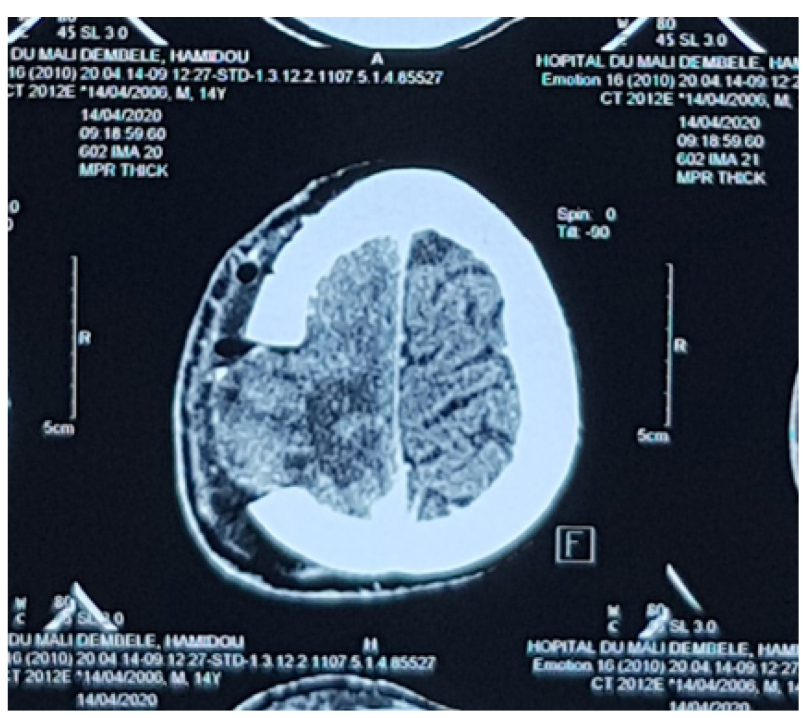

(b)

Figure 7. Cerebral CT scan axial section after contrast injection showing a subacute right upper parietal cortical hypodense range with slight cortical atrophy and small cerebral hernia through the craniotomy slit.

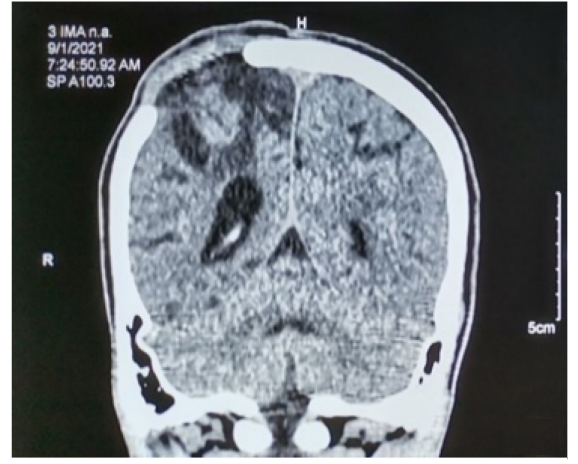

(a)

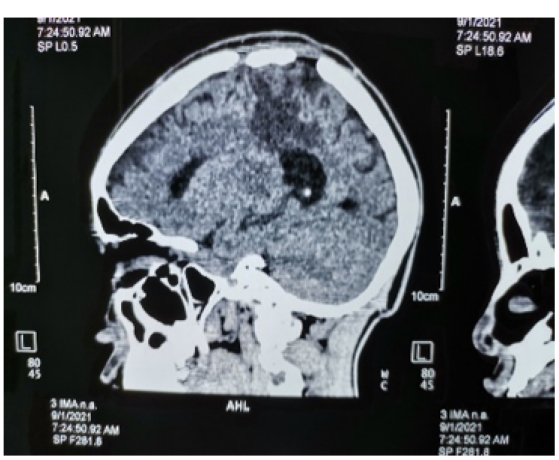

(b)

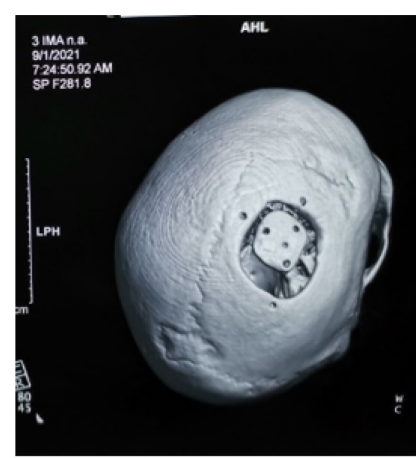

(c)

Figure 8. (a) Cerebral CT scan, non-injected coronal section in parenchymal window: presence of a left parietal sequential hypodensity opposite the cranial flap; (b) Cerebral CT sagittal section in non-injected parenchymal window: presence of a justa ventricular parietal sequential hypodensity opposite the cranial flap; (c) Cranial 3D bone scan showing the craniotomy flap.

with early post prandial food vomiting. His family took him to their local health center where he was treated for a malarial attack. He was put under ambulatory treatment including artemether $40 \mathrm{mg} / \mathrm{lumefantrine} 240 \mathrm{mg}$ : 1 tablet morning and evening for 3 days orally, paracetamol $500 \mathrm{mg} / 8$ hours if pain and/or fever orally. Faced with the persistence of symptoms and the intallation of a coma he was hospitalized in the center of their locality for better management. The rapid diagnostic test for malaria carried out in the emergency room came back negative. He was then put under empirical antibiotic therapy based on ceftriaxone: 100 $\mathrm{mg} / \mathrm{Kg} /$ day direct intravenous in a single injection, gentamycin: $3 \mathrm{mg} / \mathrm{Kg} /$ day intramuscular in a single injection, metronidazole: $10 \mathrm{mg} / \mathrm{Kg} / 12$ hours in a slow intravenous injection. The evolution was marked by an emergence of coma and the appearance of left hemiplegia. To explore this motor deficit, a cerebral scan- 
ner was performed. It revealed a right hemispherical subdural empyema associated with an intracerebral abscess left basal junction with significant peri lesional edema (Figure 9(a) and Figure 9(b)) associated with pansinusitis (Figure 10(a) and Figure 10(b)), hence referral to the Mali Hospital for management. At the entrance he weighed $25 \mathrm{~kg}$ with a height of $138 \mathrm{~cm}$ and a body mass index of 13 corresponding to underweight. He had a fever of $38.5^{\circ} \mathrm{C}$. Neurologically he was conscious, well oriented and coherent. He had a flaccid left hemiplegia with conservation of peripheral sensitivity. Cardiorespiratory, digestive and otorhinolaryngological examinations were normal. The biological examinations performed on admission were:

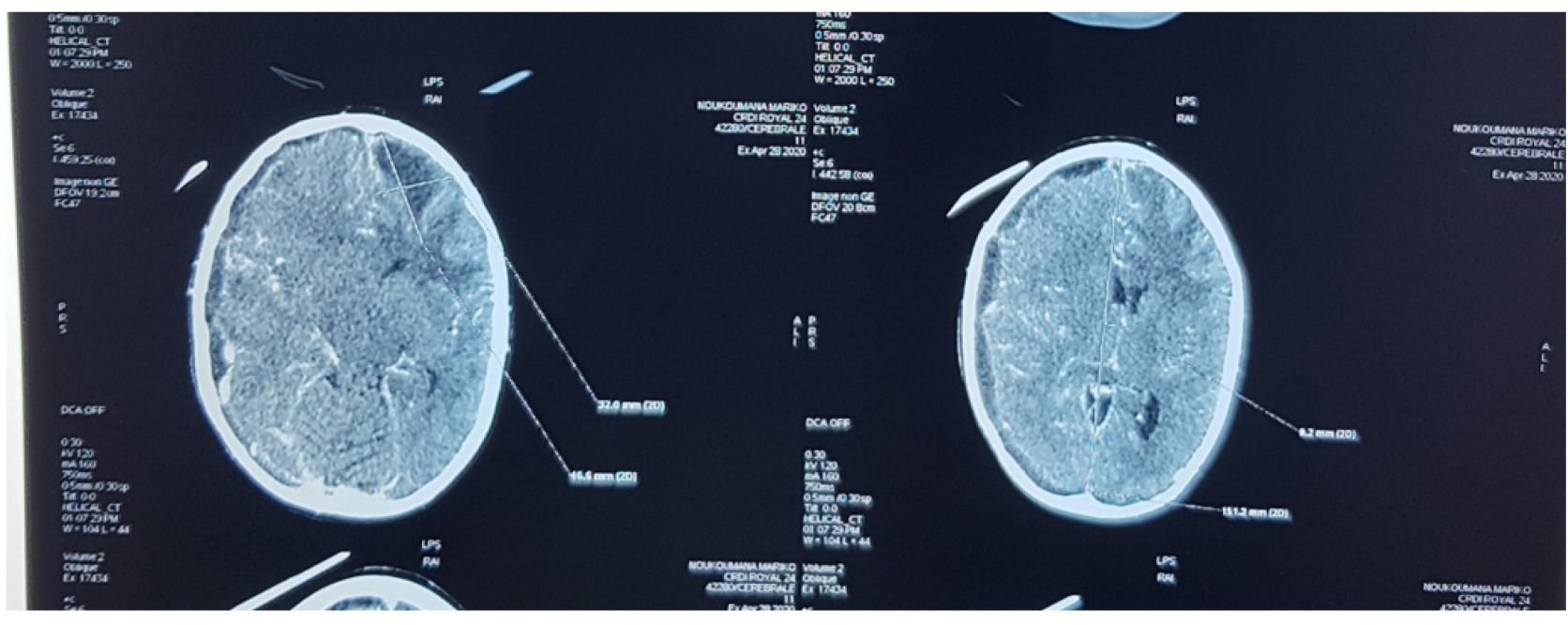

(a)

(b)

Figure 9. Cerebral scanner axial section in parenchymal window after injection of contrast medium shows: 1) a $4 \times 32 \mathrm{~mm}$ left frontal cortical abscess collection with intense annular enhancement associated with peri-lesional edematous hypodensity and discrete mass effect on the frontal horn of the homolateral ventricle; 2) right hemispherical subdural empyema (reaching $27 \mathrm{~mm}$ at the upper parietal level) responsible for mass effect on the adjacent parenchyma and midline.

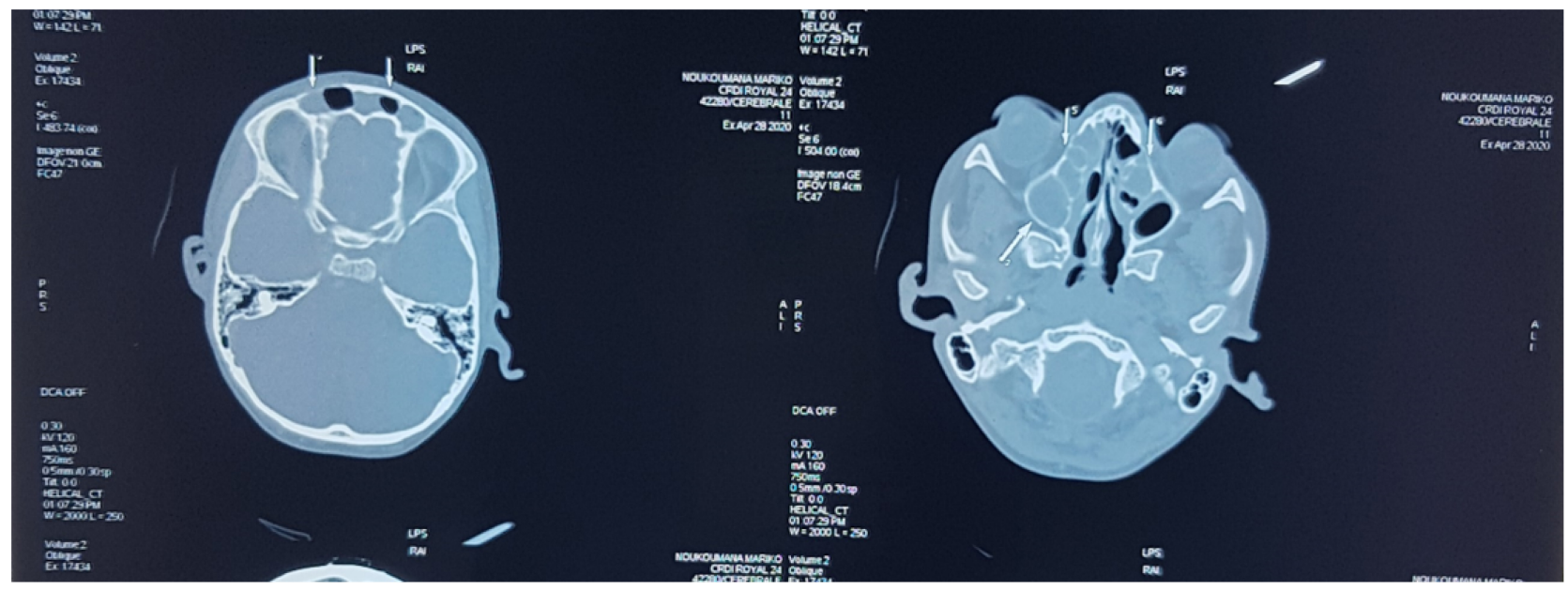

(a)

(b)

Figure 10. Brain scan bone window through the frontal and ethmoidal sinuses showing chronic, aggressive pansinusitis. 
- The hemogram which showed anemia at $6.7 \mathrm{~g} / \mathrm{dl}$ microcytic and hyperleukocytosis at $19,000 / \mathrm{mm}^{3}$ with neutrophils predominating. Platelets were at $419,000 / \mathrm{mm}^{3}$;

- C-reactive protein was elevated at $145 \mathrm{mg} / \mathrm{l}$;

- Prothrombin level was $75 \%$ and activated partial thromboplastin time was 31.9 seconds.

A medical treatment consisting of ceftriaxone $100 \mathrm{mg} / \mathrm{kg} /$ day direct intravenous in a single injection for 15 days, gentamycin; $3 \mathrm{mg} / \mathrm{kg} /$ day intramuscular in a single injection for 3 days, metronidazole: $10 \mathrm{mg} / \mathrm{kg} / 12$ hours in slow intravenous for 15 days, paracetamol: $15 \mathrm{mg} / \mathrm{kg} / 6$ hours in slow intravenous, glucose serum 10\%: $100 \mathrm{ml} / \mathrm{kg} / \mathrm{d}$ in slow intravenous and group O+ globular concentrate: 20 $\mathrm{ml} / \mathrm{Kg}$ in slow intravenous over 1 hour were instituted. The antibiotic therapy was relayed with ciprofloxacin $10 \mathrm{mg} / \mathrm{Kg} / 12$ hours for 6 weeks orally.

On the tenth day of hospitalization he was operated on. The operating technique used was: right temporo-parieto-occipito-frontal incision, craniotomy, crosswise opening of the dura mater, evacuation of the frank pus under high pressure. Bacteriological examination of the pus from the abscess isolated Staphylococcus aureus sensitive to cephalotin, ofloxacin, ceftriaxone, doxycycline, ciprofloxacin and gentamycin. It was resistant to erythromycin, lincomycin and azithromycin. The postoperative period was calm. Seven days after the operation we have apyrexia and regression of hemiplegia. The cerebral CT scan performed 2 weeks after the operation showed a small, slightly compressive right frontal extradural empyema on the cortical opposite associated with a hypodense cortico-sub cortical frontal contralateral area with atrophy of the parenchyma (Figure 11).

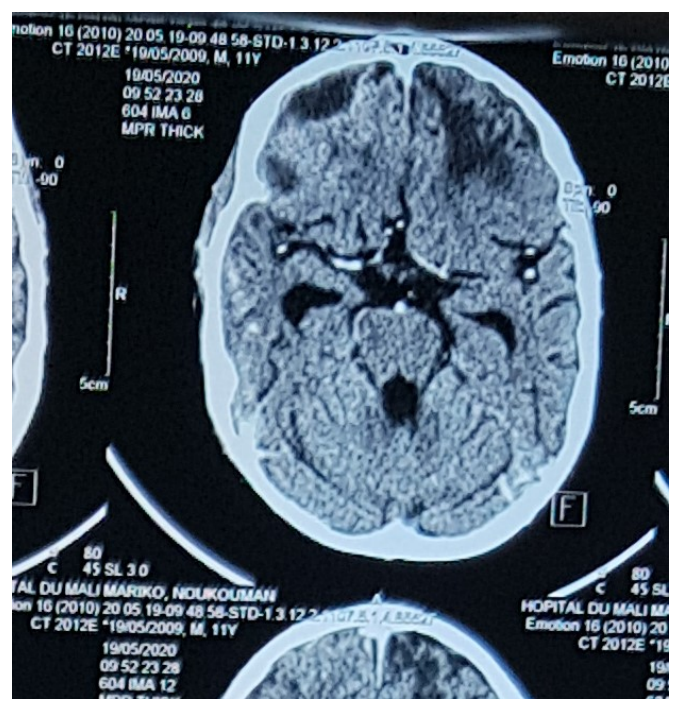

Figure 11. Cerebral CT scan performed 15 days after the operation, axial section with injection of contrast agent showing a small, slightly compressive right frontal extradural empyema on the facing cortical associated with a contralateral frontal cortical-sub cortical hypodense area with atrophy of the parenchyma. 
Eighteen months after discharge he came for a follow-up consultation. His general condition was good and he was apyretic. There was no motor deficit or sensory deficit of the left upper limb.

\section{Discussion}

The abscess is an intracranial suppuration creating a neoformed cavity. This characteristic differentiates it from a subdural or extradural empyema which is defined as an intracranial suppuration developed in a pre-existing cavity [8]. In half of the cases, these intracranial suppurations result from direct propagation from an otorhinolaryngologic or dental focus [9].

Abscesses and empyema are frequent in males with a sex ratio of about 3 males to 2 females. Cerebral abscesses can occur at any age, despite a high frequency before the age of 40 , with $25 \%$ of cases occurring before the age of 15 [3]. Extra dural empyema accounts for $15 \%$ of focal suppurations and mainly affects young subjects or children. The incidence of cerebral abscesses is estimated at four to five cases per year and per million inhabitants [3].

From a pathophysiological point of view, intracranial suppurations begin with an uncontrolled inflammation (cerebritis) secondarily surrounded by a hypervascularized capsule that limits the extension of the infection. Different doorway-dependent mechanisms are responsible for the initial cerebritis. For otorhinolaryngologic entry portals, it is contiguous contamination. They represent $50 \%$ of the cases. They develop from a primitive otorhinolaryngologic focus, frontal sinusitis, frontoethmoidal, sphenoidal, chronic otitis media or mastoiditis [8]. Spread is by intracranial venous route, favoured by septic phlebitis. The intracerebral localization depends on the source of infection. The flora is generally polymicrobial [8].

Anatomopathologically: the normal cerebral parenchyma is resistant to infection unless necrosis occurs within it. Cerebral abscesses develop mainly at the junction between white matter and gray matter in a functional territory between the superficial and deep territories of the middle cerebral artery [3].

Presuppurative encephalitis is characterized by a necrotic center containing inflammatory cells and numerous germs, surrounded by an inflammatory reaction made of macrophagic cells and fibroblasts surrounding the formation of reticulin tissue. Perivascular infiltration of polynuclear cells, mononuclear cells and neo-vessels develops around the necrotic center and the inflammatory region. The healthy brain is separated from this presuppurative encephalitis by a more pronounced white matter edema [3] [10]. At the brain abscess stage the size of the necrosis decreases while fibroblasts and macrophage cells appear at its periphery, leading to the formation of a collagen capsule whose thickness gradually increases. At this stage the neo-vessels are at their maximum development. Cerebral edema regresses and an astrocytic gliosis develops in the periphery [3] [10]. The subdural empyemas produce an extracerebral suppurated collection located between dura mater and arachnoid. It is rare for the infectious process to 
extend directly by contiguity from a sinusitis progressively forming an extra dural suppurated collection, then a sub dural partitioned collection [3] [10]. The mechanism of development of extradural empyema is close to that of subdural empyema. It is generally secondary to an infection of the middle ear or the sinus of the face [3] [10].

Clinically:

Brain abscesses can manifest themselves in a variety of ways. The site of the abscess is an important part of the symptomatology: frontal abscesses are long silent. Most often, the clinical symptomatology is that of an isolated mass syndrome with signs of intracranial hypertension (headache, vomiting], epileptic seizures, progressive focal neurological deficit. Infectious signs (fever, alteration of general condition, inflammatory syndrome) are often little marked or even absent [10].

Subdural empyema: the onset is often progressive over a fortnight. The first signs are headaches and fever occurring when antibiotic therapy for an otorhinolaryngological infection is already prescribed in most cases. The onset is often difficult to specify, as headaches and fever can also be explained by sinusitis, the most common gateway. Unilateral palpebral edema may also be observed [3]. In this low-noise picture, after 1 or 2 weeks, a sudden or rapid focal neurological deficit occurs with signs of cortical damage: focal or generalized epileptic seizures and disturbances of upper functions, intracranial hypertension with a moderate infectious syndrome [3].

Extradural empyema, unlike subdural empyema, evolves insidiously sometimes even without fever, their symptomatology being limited to a few headaches and a minimum of neurological signs in the aftermath of infection or otorhinolaryngological surgery. Low-dose antibiotics alleviate the symptomatology and mask the severity of these empyema without preventing rapid decompensation [3].

Our clinical cases are endocranial suppurations of sinus origin in adolescents of 11 and 14 years old. This age group was reported by Passeron $\mathrm{H}$ et al. [1] who in their study conducted at the Hôpital Principal de Dakar in Senegal in 2004 found an average age of 11.2 years. They were all boys. This male predominance was reported by most of the authors, including Passeron $\mathrm{H}$ et al. [1] and Miloundja J et al. [7] who reported a sex ratio of 3 and 1.6 in favour of boys, respectively. Fever, headache and hemiplegia were their reasons for hospitalization. These symptoms are classic clinical manifestations of endocranial suppurations described in the literature [3] [8]. The diagnosis of endocranial suppurations was made by brain CT scan with injection of contrast agent in our 3 patients. This examination was described by Ponsot G [2] and S. Riehm [11] as a test of choice in the management of endocranial suppurations. It showed subdural empyemas in two patients and a subdural empyema associated with a parenchymal collection in one patient. Subdural empyema was associated with pansinusitis in one patient, and in two patients, multifocal sinusitis was associated with sphenoidal 
sinus sparing. These findings are different from those reported by B. Hammammi et al. [12], who in their study found that $33 \%$ of endocranial complications of acute sinusitis are sphenoidal in origin. Brain CT revealed in one of our clinical cases a right intraorbital collection in addition to multifocal sinusitis. This ocular damage was described by B. Hammammi et al. [12] who reported in their study that orbital complications are frequent in ethmoidal sinusitis. Bacteriological analysis of pus was sterile in 2 of our patients and isolated cephalotin-sensitive Staphylococcus aureus, ofloxacin, ceftriaxone, doxycycline, ciprofloxacin and gentamicin from one patient. This can be explained by the fact that our 3 patients received antibiotics prior to admission. This result is close to that reported by Passeron $\mathrm{H}$ et al. [1] who isolated Staphylococcus aureus in $12.5 \%$ of their patients and ungroupable streptococcus in $12.5 \%$. Neurosurgical drainage combined with antibiotic therapy including ceftriaxone, gentamycin and metronidazole was instituted in our 3 patients as reported by Passeron $\mathrm{H}$ et al. [1] in their study. None of our children had sinus drainage contrary to the study of Miloundja [7] et al. who performed this intervention in 2 out of 5 children in their study. The post-operative period was calm in all three of our children.

\section{Conclusion}

Endocranial suppurations of sinus origin are serious and frequent infections in children in developing countries due to unfavorable socio-economic conditions. Fever, headache and motor deficits are classic clinical manifestations. Its prognosis depends on the early diagnosis. It should be mentioned in the case of any hemiplegia associated with fever or headache and confirmed by a brain scan with injection of a contrast agent.

\section{Conflicts of Interest}

The authors declare no conflicts of interest regarding the publication of this paper.

\section{References}

[1] Passeron, H., Sidy Ka, A., Diakhaté, I. and Imbert, P. (2010) Suppurations intracrâniennes à porte d'entrée otorhinolaryngologique chez l'enfant au Sénégal. Archives de Pédiatrie, 17, 132-140. https://doi.org/10.1016/j.arcped.2009.11.001

[2] Ponsot, G. (2001) Collection suppurées intracraniennes et médulaires. In: Neurologie pédiatrique. Médecines Sciences Flammarion, Flammarion, Paris, 515-519.

[3] Leys, D. (2004) Abcès cérébraux et empyèmes intracrâniens. EMC-Neurologie, 1, 1-7. https://doi.org/10.1016/S0246-0378(01)00092-6

[4] Ennaciri, Z., Lmejjati, M. and Benali, S.A. (2011) La prise en charge de l'abcès cérébral au service de Neurochirurgie CHU Mohammed VI. http://wd.fmpm.uca.ma/biblio/theses/annee-htm/art/2011/article95-11.pdf

[5] Hilmani, S., Riyahi, S., Ibahioin, K., Naja, A., El Kamar, A. and El Azhari, A. (2009) Les abcès cérébraux (à propos de 80 cas). Neurochirurgie, 55, 40-44. https://doi.org/10.1016/j.neuchi.2008.10.012 
[6] Broalet, M.Y.E., N’dri Oka, D., Eholie, S., Guillao-Lasme, E., Varlet, G. and Bazeze, V. (2012) Clinical studies/études cliniques abcès et empyèmes intracrâniens chez l'enfant cerebral abcess and intracranial empyemas in children. African Journal of Neurological Sciences, 21, 2. https://doi.org/10.4314/ajns.v21i1.7517

[7] Miloundja, J., Bamba, J.S., Mouba, J.F., Ella Ondo, T., Mwanyombet, L., Mandji Lawson, J.M., et al. (2011) Cranioencephalic Complications of Bacterial Sinusitis in Children and Adolescents: Eight Cases in Libreville (Gabon). Cahiers Santé, 21, 215-220.

[8] Laurichesse, J., Souissi, J, and Leport, C. (2009) Abcès du cerveau. In: Traité de médecine Akos, Elsevier-Masson, Mayotte, 1-4. https://doi.org/10.1016/S1634-6939(09)45383-3

[9] Laval, N., Demonceau, N. and Khamis, J. (2018) Abcès cérébral et trouble aigu du comportement chez un enfant. Revue Médicale de Liège, 73, 53-55.

[10] Sarrazin, J.-L., Bonneville, F. and Martin-Blondel, G. (2012) Infections cérébrales. Journal de Radiologie Diagnostique et Interventionnelle, 93, 503-520. https://doi.org/10.1016/j.jradio.2012.03.003

[11] Riehm, S. and Veillon, F. (2011) Complications méningo-encéphaliques des infections ORL. Journal of Radiology, 92, 995-1014.

[12] Hammami, B., Masmoudi, M., Charfeddine, I., Mnejja, M. and Ghorbal, A. (2014) Prise en charge des complications orbitaires et endocrâniennes des sinusites bacteriennes aiguës. Journal Tunisien d'ORL et de Chirurgie Cervico-Faciale, 31, 2-6. 